\title{
Correlations among plasma silicon, magnesium and calcium in patients with knee osteoarthritis - analysis in consideration of gender
}

\author{
Irena Musik',A,D,F, Jacek Kurzepa ${ }^{1, D-E}$, Dorota Luchowska-Kocot ${ }^{1, C}$, Joanna Kocot ${ }^{1, C}$, \\ Marek Paździor ${ }^{2, B}$, Małgorzata Polz-Dacewicz ${ }^{3, E}$, Małgorzata Kiełczykowska, ${ }^{1, D-E}$ \\ ${ }^{1}$ Chair and Department of Medical Chemistry, Medical University, Lublin, Poland \\ 2 Traumatic-Orthopaedic and Spine Surgery Ward, Independent Public Health Care Centre, Puławy, Poland \\ ${ }^{3}$ Department of Virology, Medical University, Lublin, Poland \\ A - Research concept and design, B - Collection and/or assembly of data, C - Data analysis and interpretation, \\ $D$ - Writing the article, E - Critical revision of the article, F - Final approval of article
}

Musik I, Kurzepa J, Luchowska-Kocot D, Kocot J, Paździor M, Polz-Dacewicz M, Kiełczykowska M. Correlations among plasma silicon, magnesium and calcium in patients with knee osteoarthritis - analysis in consideration of gender. Ann Agric Environ Med. 2019; 26(1): 97-102. doi: 10.26444/aaem/92277

\begin{abstract}
Introduction and objective. Osteoarthrits $(\mathrm{OA})$ is a complex, chronic disorder of cartilage and bone, related to homeostasis of bioelements. The current study aimed at evaluation of correlations between plasma silicon, magnesium and ionized calcium in OA patients in consideration to gender.

Materials and method. The study comprised 59 patients aged $69.5 \pm 9.0$ years (18 males aged 66.8 $\pm 9.2 ; 41$ females aged $70.7 \pm 8.8)$, admitted to the Trauma and Orthopaedic Ward of the Independent Public Health Care Centre in Łęczna, Poland, due to OA and qualified to surgery. Control group consisted of 19 subjects without OA ( $54.5 \pm 8.6$ years; 10 males aged 41.3 $\pm 9.3 ; 9$ females aged 69.1 \pm 14.9 ). Plasma concentrations of silicon and magnesium (spectrophotometric methods) and ionized calcium (potentiometric method) were determined.

Results. Silicon in OA patients was significantly increased vs. control. In OA males and OA females, silicon was enhanced vs. the respective controls, but it was statistically significant only in males. Magnesium in OA patients was not significantly different from control group. In females, a significant decrease vs. the respective control was observed. No significant differences were observed in the case of ionized calcium. Positive correlations between silicon and magnesium in healthy control, both in the whole group and in male and female subgroups, were noted, while no such effect was observed in OA subjects.

Conclusions. The results might suggest some connection between higher OA incidence in women and the depleted magnesium in the organism. Silicon increase in OA patients, especially in men, may indicate its intense metabolism during the articular inflammatory process, likely dependent on sex hormones. It remains open whether the plasma Si increase is the effect or cause of OA.
\end{abstract}

Key words

osteoarthritis of knee, silicon, calcium, magnesium, males, females

\section{INTRODUCTION}

Osteoarthrits (OA) is a complex, chronic disorder of the musculoskeletal system. Its course involves disturbances of balance between regeneration and degeneration of articular cartilage connected with damage to subchondrial bone, as well as the inflammation process [1-5]. The consequences of these pathological processes are joints stiffness and pain, which negatively affect life quality and, along with the disease development, can lead to functional disability to such a considerable a degree that its consequence may even result in early withdrawal from work [6, 7]. OA occurs most often in cases of knee and hip joints. Its incidence increases along with ageing [8] and shows dependency on gender. Generally, considerable differences in the incidence of diverse diseases, including osteoarthritis between males and females, have been found [9]. In the case of OA, women are the group at higher risk. Additional risk factors are obesity, genetic

Address for correspondence: Małgorzata Kiełczykowska, Chair and Department of Medical Chemistry, Medical University of Lublin, Lublin, Poland, Chodźki 4 a, 20-093 Lublin, Poland

e-mail: malgorzata.kielczykowska@umlub.pl

Received: 24.05.2018; accepted: 14.06.2018; first published: 25.07.2018 predisposition, disturbances of the neuromuscular system as well as metabolic disorders [10-12]. OA of knee joint can also be a consequence of mechanical trauma as well as selenium deficit or disturbances of calcium homeostasis [13-15]. The development and course of OA has been revealed to be affected by diet and physical activity $[16,17]$.

Research performed to date has revealed a relationships between homeostasis of both bioelements, with OA course and patients' condition $[4,8,14,18]$. Even boron, an element rather rarely used in human model experiments, has been reported to be a possible therapeutical agent in OA subjects. Interestingly, in one of the studies, it was applied in the form of calcium fructoborate [1].

Calcium, the second most abundant extracellular macroelement, apart from being a bone component, influences numerous physiological processes, neurotransmission, hormone secretion and blood clotting, among others [19-21]. The relationships between serum calcium level, as well as vitamin $\mathrm{D}$ treatment and knee OA development, have also been reported, pointing to the importance of this element's homeostasis for OA subjects $[2,14]$.

Magnesium belongs to one of the most important macroelements whose metabolic role involves processes 
related to osteoarthritis. It influences the inflammatory cytokines level and acts as a pain mediator [18], as well as affecting muscle function. Dietary $\mathrm{Mg}$ has been found to prevent age-related depletion of muscle condition [22]. The beneficial effect of higher dietary or blood magnesium in cases of cartilage and bone disorders, including osteoarthritis or chondrocalcinosis as well as frailty, has been reported $[23,24]$.

Silicon is a microelement whose role and essentiality for the human organism remains unclear [25]. However, in view of the available research data its connection with the functioning of connective tissues seems to be unquestionable $[26,27]$. An association has been found between dietary silicon and bone condition in humans [28]. Moreover, the associations between silicon metabolism and female hormones have been investigated and relationships of $\mathrm{Si}$ bone metabolism with oestrogen status revealed [25, 29]; however, other authors did not find any correlations of its absorption and excretion with oestradiol [30]. Additionally, the differences between the male and female studied groups regarding the beneficial influence of silicon preparation treatment in knee OA patients have been reported [31]. Some interactions between silicon and other elements have also been observed $[32,33]$. In one of the newest studies, silicon and strontium ions together have been reported to promote cartilage and bone regeneration [5].

\section{OBJECTIVE}

The aim of the study was to determine ionized calcium, magnesium and silicon in plasma of OA patients qualified to surgery, as well as to evaluate the possible correlations among the studied bioelements. Taking into account that men and women have shown considerable differences as to the risk of OA incidence and response to treatment, the obtained results were also analysed in consideration of gender.

\section{MATERIALS AND METHOD}

Information about the purpose of the study was provided to all the participants and written consent was obtained from all those enrolled into the study.

The study was performed with the approval of the Bioethical Board of the Medical University of Lublin (Acceptance No. KE-0254/11/2016).

Patients. The study comprised 59 patients aged $69.5 \pm 9.0$ years (18 males aged $66.8 \pm 9.2$; 41 females aged $70.7 \pm 8.8$ ), admitted to the Trauma and Orthopaedic Ward of the Independent Public Health Care Centre in Łęczna (Lublin Province, Eastern Poland), due to knee osteoarthritis and qualified for surgery. The knee osteoarthritis was diagnosed based on medical history, physical examination, X-ray, ultrasound or computed tomography scan of the knee joint.

Inclusion criteria were the overall condition allowing surgery under extrameningeal or general anaesthesia, limited physical activity, degeneration changes based on image examination. Exclusion criteria were infection of the joint or its region, body mass index $(\mathrm{BMI})>30.0 \mathrm{~kg} / \mathrm{m}^{2}$, smoking, blood clotting disorders, taking magnesium, calcium or silicon supplements, and limb ischaemia, as well as varicose veins accompanied by thrombophlebitis.
The patients were treated with: nonsteroidal antiinflammatory drugs and additional adjuvants (collagen, glucosamine, chondroitin, hyaluronic acid preparations and steroids).

The control group included 19 subjects without osteoarthritis, inflammation or calcium, magnesium and silicon supplementation. The average age was $54.5 \pm 18.6$ years (10 males aged $41.3 \pm 9.3$; 9 females aged $69.1 \pm 14.9$ ).

The studied groups were denoted as follows: CONTROL - the control group without regard to gender; C-male male control subjects; C-female - female control subjects; PATIENTS - knee osteoarthritis patients without regard to gender; P-male - male knee osteoarthritis patients; P-female - female knee osteoarthritis patients.

A sample of blood was drawn from each participant during standard biochemical examinations.

Biochemical determinations. Fasting (after 12-hour overnight fasting) blood samples were drawn from patients and control subjects using heparinized test-tubes. Plasma was separated by centrifugation at 3,000 rpm for $10 \mathrm{~min}$. and stored at $-20^{\circ} \mathrm{C}$ for further determinations.

Plasma concentrations of silicon was measured using spectrophotometric methods according to Wielkoszyński [34]. Plasma magnesium concentration was assayed by the colorimetric method using commercially available diagnostic kit Liquick Cor-MG 60 (Cormay, Łomianki, Poland).

Determinations of silicon and magnesium were performed using spectrophotometer SPECORD M40 (Carl Zeiss, Jena, Germany). Ionized calcium was determined in plasma by potentiometric method with using ion-selective electrode and analyzer COBAS D221 (Roche, Basel, Switzerland)

Statistics. All statistical analyses were performed using the STATISTICA 12 programme. The normality of data distribution was verified using Shapiro-Wilk test. Normally distributed variables were expressed as mean \pm SD, while non-normally distributed ones as median and quartile distribution. The differences among the studied groups were analysed using the t-Student test (for normally distributed variables) or the U Mann Whitney test (for non-normally distributed variables). Values were considered significant with $\mathrm{p}<0.05$. For evaluating of correlations among the studied elements, Pearson (normal distribution) or Spearman (nonnormal distribution) correlations coefficients were calculated.

Having taken into consideration the difference in ages between male OA subjects and male controls (P-male and C-male groups) multi-way analysis of variance ANOVA/ MANOVA in these groups was performed. To unify the results, the same analysis was also performed for female patients and control groups.

\section{RESULTS}

Silicon in plasma of patients was significantly increased compared to control with $\mathrm{p}<0.001$ (Fig. 1). The comparison performed taking gender into account showed that in males plasma silicon was significantly increased vs. male control group with $\mathrm{p}<0.001$. In females, an enhancement vs. the respective control was also observed, but it did not reach statistical significance $(\mathrm{p}<0.11)$ (Fig. 1). Magnesium in plasma of patients was not significantly different from control group; 


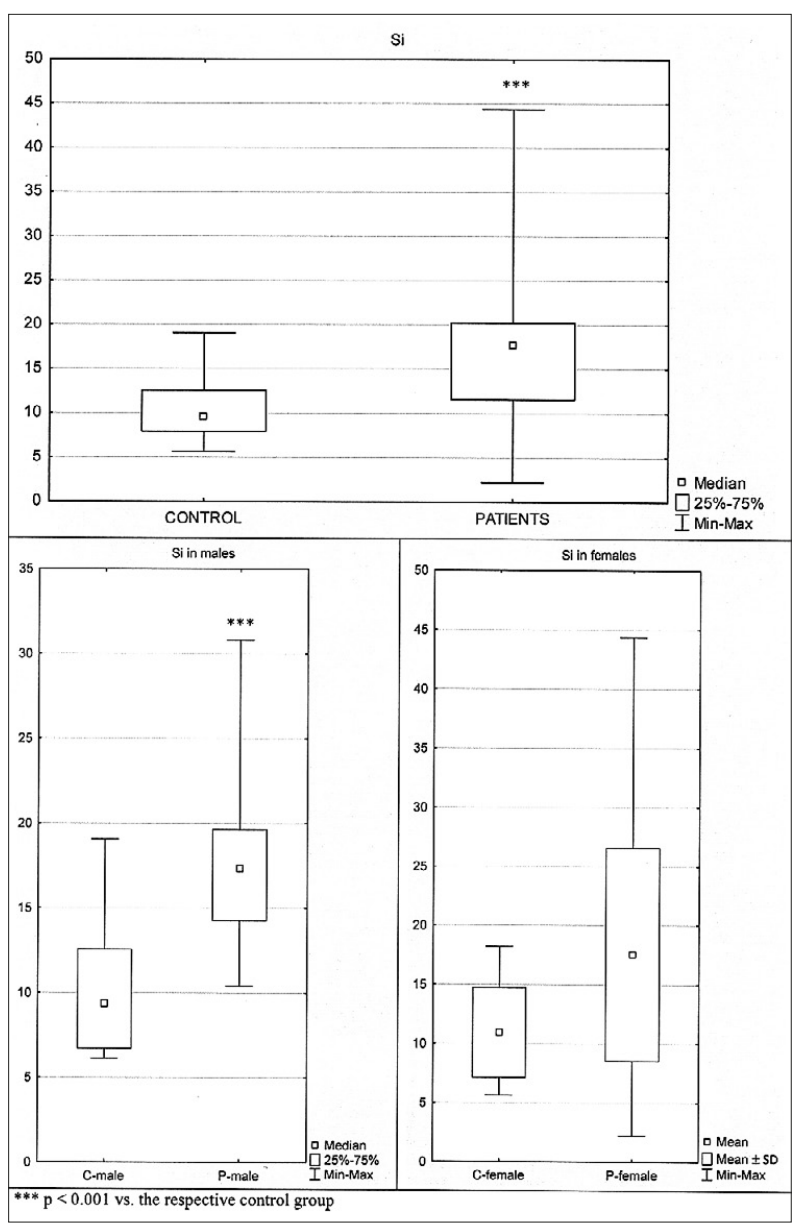

Figure 1. Silicon concentration $\left[\mu \mathrm{mol} / \mathrm{dm}^{3}\right]$ in plasma

however, a slight decrease was observed $(\mathrm{p}<0.2)$ (Fig. 2).

The comparison performed taking gender into consideration showed essential differences between males and females. In males, an insignificant increase was observed compared to the proper control $(\mathrm{p}<0.1)$, while in females, a significant decrease vs. the respective control group $(\mathrm{p}<0.01)$ was noted (Fig. 2).

Calcium in plasma of patients was not significantly different from control group (Fig. 3).

The comparison performed with taking into consideration the gender showed that both in males and in females the obtained values did not show significant differences vs. the respective control groups (Fig. 3).

The multi-way analysis of variance ANOVA/MANOVA showed that in males age had no effect on the differences between P-male and C-male groups ( $\mathrm{Si}$ : $\mathrm{F}=0.032 ; \mathrm{p}=0.968$; $\mathrm{Mg}: \mathrm{F}=1.065 ; \mathrm{p}=0.350 ; \mathrm{Ca}: \mathrm{F}=1.275 ; \mathrm{p}=0.286$ ). To unify the presentation of the obtained results the same analysis was performed for females (P-female and C-female), which resulted in no relationships being found between age and the studied bioelements ( $\mathrm{Si}: \mathrm{F}=0.030 ; \mathrm{p}=0.970 ; \mathrm{Mg}: \mathrm{F}=0.349$; $\mathrm{p}=0.707 ; \mathrm{Ca}: \mathrm{F}=0.469 ; \mathrm{p}=0.629$ ).

To confirm the above results, the analysis of correlations between age and the studied parameters was performed both in males (P-male and C-male) and females (P-female and $\mathrm{C}$-female), but no correlations were found.

Statistical analysis showed the existence of positive correlations between silicon and magnesium in healthy control, both in the whole group and in the subgroups of

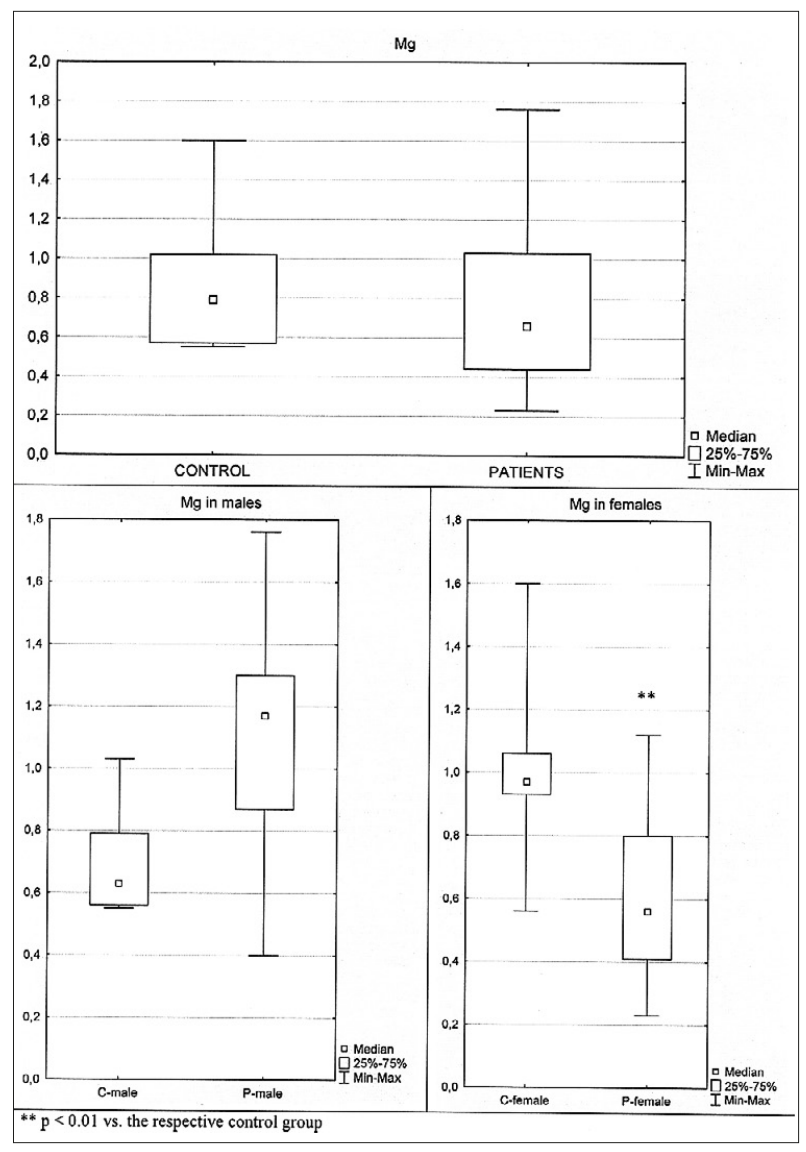

Figure 2. Magnesium concentration $\left[\mathrm{mmol} / \mathrm{dm}^{3}\right]$ in plasma

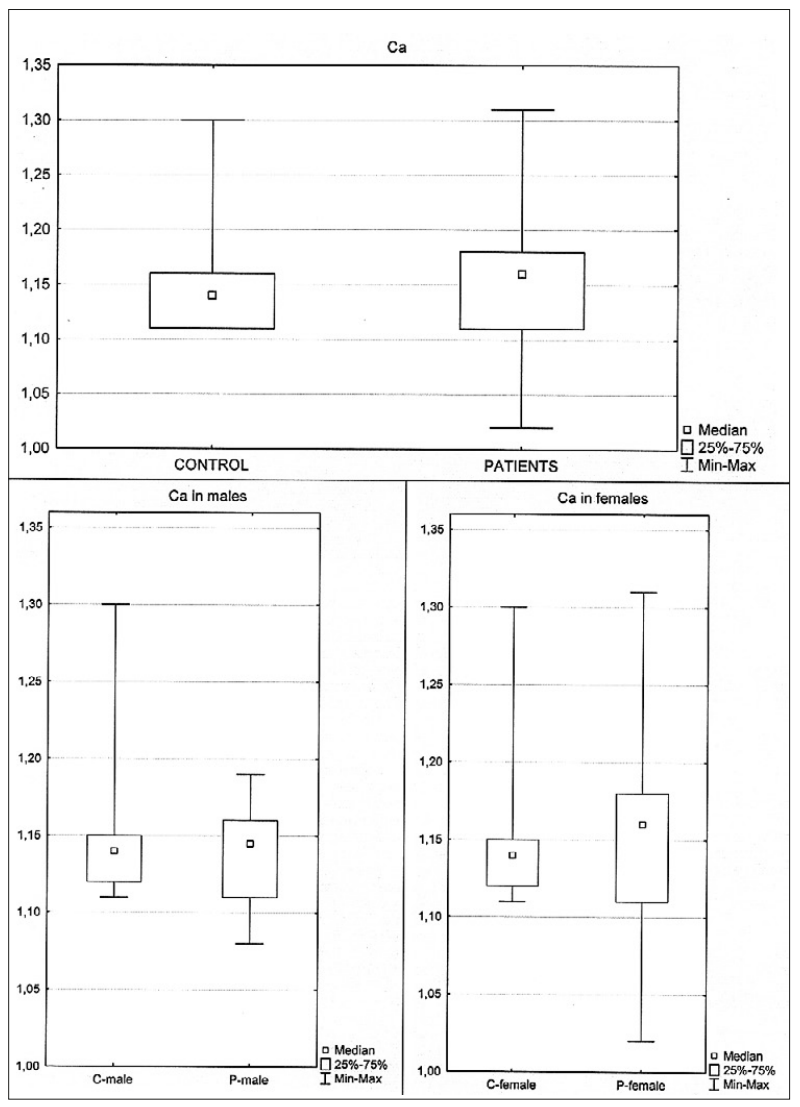

Figure 3. Calcium concentration $\left[\mathrm{mmol} / \mathrm{dm}^{3}\right]$ in plasma 
males and females, while no significant correlations were observed between silicon and calcium, and magnesium and calcium. In contrast, no significant correlations among the studied bioelements were noted in the patients. The calculated values of Pearson or Spearman correlations coefficients are shown in Table 1.

Table 1. Spearman or Pearson correlations coefficients

\begin{tabular}{lllllll}
\hline \multirow{2}{*}{ Group } & \multicolumn{3}{c}{$\mathrm{Si}-\mathrm{Mg}$} & & \multicolumn{3}{c}{$\mathrm{Si}-\mathrm{Ca}$} & \multicolumn{2}{c}{$\mathrm{Mg}-\mathrm{Ca}$} \\
\cline { 2 - 7 } & $\mathrm{R}$ & $\mathrm{p}$ & $\mathrm{R}$ & $\mathrm{p}$ & $\mathrm{R}$ & $\mathrm{p}$ \\
\hline
\end{tabular}

\begin{tabular}{lllllll}
\hline Control & $0.5659 *(S)$ & 0.0116 & $-0.2786(S)$ & 0.2481 & $-0.1347(S)$ & 0.5826
\end{tabular}

\begin{tabular}{lllllll}
\hline Control male & $0.7112 *(S)$ & 0.0211 & $-0.1631(\mathrm{~S})$ & 0.6525 & $-0.3020(\mathrm{~S})$ & 0.3963
\end{tabular}

\begin{tabular}{lllllll}
\hline Control female & $0.7329 *(P)$ & 0.0247 & $-0.5232(S)$ & 0.1483 & $-0.5064(S)$ & 0.1642
\end{tabular}

\begin{tabular}{llllllll}
\hline Patients & $-0.0156(\mathrm{~S})$ & 0.9068 & $-0.0381(\mathrm{~S})$ & 0.7746 & $-0.0229(\mathrm{~S})$ & 0.8634
\end{tabular}

\begin{tabular}{llllllll}
\hline Patients male & $-0.0517(\mathrm{~S})$ & 0.8385 & $0.2662(\mathrm{~S})$ & 0.2856 & $0.0451(\mathrm{P})$ & 0,8590
\end{tabular}

\begin{tabular}{llllllll}
\hline Patients female & $-0.0693(P)$ & 0.6667 & $0.0276(P)$ & 0.8638 & $-0.0470(P)$ & 0.7704
\end{tabular}

${ }^{*} \mathrm{p}<0.05$; (S) - Spearman correlations coefficients; (P) - Pearson correlations coefficients

\section{DISCUSSION}

Osteoarthritis usually occurs in the elderly and analysis of its incidence, performed on a group of 1,380 subjects, revealed that it was more frequent in women in a very significant way $(p<0.0001)$ [9]. Significant differences were found between the genders, both with regard to the effects of the therapy, as well as the influence of diet and blood level of bioelements. Geusens et al. studied the effect of cholinestabilized orthosilicic acid in knee OA patients and found no considerable improvement in clinical parameters (pain, stiffness), nor in cartilage degradation biomarkers (urine C-terminal telopeptide of collagen type II and serum cartilage oligomeric matrix protein). However, analysis of the obtained results with respect to gender revealed significant differences. In men, OA symptoms were reduced and accompanied by a significant depletion of markers of cartilage degradation. No such effect was observed in women. According to the authors, such results might be connected with the fact that the female subjects were mostly postmenopausal, and the serum baseline estradiol in this group was much lower than in males. This made the 12 -week treatment too short and consequently ineffective [31]. Such conclusions are consistent with the results reported by Macdonald et al. who stated that silicon influence on bone condition was affected by oestrogen status. A significant relationship between energyadjusted dietary intake of silicon and bone mineral density of the femoral neck was found only in oestrogen-replete females, whereas in perimenopausal or postmenopausal women without hormone replacement therapy (HRT) such marked associations were not observed [25]. Similarly, having compared the connections between silicon intake with diet and bone mineral density in different study groups, (premenopausal women, postmenopausal women with or without HRT, as well as men) Jugdaohsingh et al. suggested the involvement of oestradiol in the Si utilization at the cellular level [30].

The importance of silicon in the case of osteoarthritis was recently confirmed by Deng et al. who studied the potential beneficial influence of $\mathrm{Sr}_{5}\left(\mathrm{PO}_{4}\right)_{2} \mathrm{SiO}_{4}$ (SPS) scaffolds on reconstruction of osteochondral defects. An in vitro experiment performed on chondrocytes using SPS extracts and an in vivo one carried out on rabbits, both showed that SPS scaffold may support osteochondral regeneration. The authors attributed this beneficial effect to Sr and Si ions released from SPS scaffold [5].

The current study shows a positive correlation between $\mathrm{Si}$ and $\mathrm{Mg}$ in control subjects, particularly in women, and the lack of any such relationship in osteoarthritis patients. Interactions between silicon and other bioelements have already been reported. Ratcliffe et al. stated that in Si-depleted rats, urinary phosphorus excretion was higher compared to Si-repleted animals [33]. Additionally, in one of the newest studies the differences in $\mathrm{Mg}$-Si correlations between subjects with healthy veins and those with insufficient veins were reported [35].

In the presented study the considerable differences with regard to silicon were observed between the knee OA patients and control without OA. Moreover, considerable differences were observed when the studied groups were divided with respect to gender. The elevation of plasma silicon in $\mathrm{OA}$ patients may be potentially caused by the intense rebuilding of cartilage and the release of silicon into the blood. The observed increase in silicon, especially in male OA patients, cannot be explained by the average age difference between $\mathrm{OA}$ and control group. Bissé et al. showed that silicon plasma level is slightly reduced with age [36]. In the current study, OA male patents were older compared to controls, however, in them the concentration of silicon was significantly higher. Silicon in females did not differ from the respective female control.

In the presented study, magnesium was found to be significantly decreased in the $\mathrm{P}$-female group in comparison with C-female group. In view of the available literature data, this seems to be consistent with the fact that in women the incidence of osteoarthritis is higher. The research confirmed the importance of magnesium homeostasis in subjects suffering from OA. In a study including 2,548 participants with radiographic knee, OA lower intake of magnesium was shown to be correlated with worsened knee functioning and pain [18]. A similar conclusion about the significance of maintaining a proper magnesium level can be drawn from the results reported by $\mathrm{Li}$ et al., who revealed that serum and dietary $\mathrm{Mg}$ were associated in an inverse way with serum concentration of the high-sensitivity C-reactive protein in subjects with early radiographic knee OA. Taking into account that low magnesium could contribute to inflammatory response, the authors suggested that their outcomes may be useful in the therapy of early knee OA [4]. Another study on 1,626 subjects which confirmed the importance of magnesium in the course of knee OA was performed by Zeng et al. The authors found an inverse relationship between magnesium intake with diet and both radiographic knee OA and joint space narrowing [8]. Interesting results were obtained by Veronese et al. according to whom, in a group of 4,421 subjects aged $45-79$ years with knee OA or its high risk, during the subsequent 8 -year-follow up the higher dietary magnesium decreased the risk of frailty development in males, while no such relationship was noted in females [24].

The present study revealed no associations between ionized plasma calcium and osteoarthritis incidence. The available data concerning the relationships between cartilage as well as bone disorders and calcium homeostasis are not consistent. Resmini et al. investigated serum ionized calcium 
in patients with hip OA, but did not observe differences between subgroups with and without (normal femoral bone density) osteoporosis [37]. In a cross-sectional study including 5,880 subjects, performed by Lee, no significant correlation between knee osteoarthritis and endogenous parathyroid hormone was found, although in women a trend for a negative trend was observed [38]. In contrast, serum calcium was reported to be associated in an inverse way with radiographic knee osteoarthritis [14]. The existence of relationships between calcium serum level and the course of disease were also confirmed by Sanghi et al. who studied the influence of 12-month-supplementation with vitamin D on the condition of knee osteoarthritis subjects with vitamin $\mathrm{D}$ deficiency. Compared to a placebo group, supplemented patients showed a significant improvement in functioning and decreased pain. These effects were accompanied by enhancement of serum total and ionic calcium [2].

\section{CONCLUSIONS}

The outcomes of the current study might suggest that the higher OA incidence observed in women could, in some part, be connected with the depleted magnesium in the organism. Increased concentration of silicon in patients with OA, especially in men, may indicate an intense metabolism of this element during articular inflammatory process, and likely to be dependent to sex hormones. However, the question remains open whether the increase in Si concentration in the plasma is the cause or effect of OA.

\section{Conflict of interest}

The authors declare that they have no conflict of interest.

\section{REFERENCES}

1. Scorei R, Mitrut P, Petrisor I, Scorei I. A double-blind, placebocontrolled pilot study to evaluate the effect of calcium fructoborate on systemic inflammation and dyslipidemia markers for middle-aged people with primary osteoarthritis. Biol Trace Elem Res. 2011; 144(1-3): 253-263.

2. Sanghi D, Mishra A, Sharma AC, Singh A, Natu SM, Agarwal S, et al. Does vitamin D improve osteoarthritis of the knee: a randomized controlled pilot trial. Clin Orthop Relat Res. 2013; 471(11): 3556-3562.

3. Yazmalar L, Ediz L, Alpayci M, Hiz O, Toprak M, Tekeoglu I. Seasonal disease activity and serum vitamin D levels in rheumatoid arthritis, ankylosing spondylitis and osteoarthritis. Afr Health Sci. 2013; 13(1): 47-55.

4. Li H, Zeng C, Wei J, Yang T, Gao SG, Luo W, et al. Associations of dietary and serum magnesium with serum high-sensitivity C-reactive protein in early radiographic knee osteoarthritis patients. Mod Rheumatol. 2017; 27(4): 669-674.

5. Deng C, Zhu H, Li J, Feng C, Yao Q, Wang L, et al. Bioactive Scaffolds for Regeneration of Cartilage and Subchondral Bone Interface. Theranostics. 2018; 8(7): 1940-1955.

6. Jung JH, Seok H, Choi SJ, Bae J, Lee SH, Lee MH, et al. The association between osteoarthritis and sleep duration in Koreans: a nationwide cross-sectional observational study. Clin Rheumatol. 2018; https:// link.springer.com/content/pdf/10.1007\%2Fs10067-018-4040-3.pdf

7. Laires PA, Canhão H, Rodrigues AM, Eusébio M, Gouveia M, Branco JC. The impact of osteoarthritis on early exit from work: results from a population-based study. BMC Public Health. 2018; 18(1): 472.

8. Zeng C, Li H, Wei J, Yang T, Deng ZH, Yang Y, et al. Association between Dietary Magnesium Intake and Radiographic Knee Osteoarthritis. PLoS One. 2015; 10(5): e0127666.

9. Corrao S, Santalucia P, Argano C, Djade CD, Barone E, Tettamanti $\mathrm{M}$, et al. Gender-differences in disease distribution and outcome in hospitalized elderly: Data from the REPOSI study. Eur J Intern Med. 2014; 25(7): 617-623.

10. Chang AH, Lee SJ, Zhao H, Ren Y, Zhang LQ. Impaired varus-valgus proprioception and neuromuscular stabilization in medial knee osteoarthritis. J Biomech. 2014; 47(2): 360-366.

11. Wallace IJ, Worthington S, Felson DT, Jurmain RD, Wren KT, Maijanen $\mathrm{H}$, et al. Knee osteoarthritis has doubled in prevalence since the mid20th century. Proc Natl Acad Sci U S A. 2017; 114(35): 9332-9336.

12. Hussain SM, Wang Y, Giles GG, Graves S, Wluka AE, Cicuttini FM. Female reproductive and hormonal factors and incidence of primary total knee arthroplasty due to osteoarthritis. Arthritis Rheumatol. 2018; https://onlinelibrary.wiley.com/doi/epdf/10.1002/art.40483

13. Jordan JM. An Ongoing Assessment of Osteoarthritis in African Americans and Caucasians in North Carolina: The Johnston County Osteoarthritis Project. Trans Am Clin Climatol Assoc. 2015; 126: 77-86.

14. Li H, Zeng C, Wei J, Yang T, Gao SG, Li YS, et al. Serum Calcium Concentration Is Inversely Associated With Radiographic Knee Osteoarthritis: A Cross-Sectional Study. Medicine (Baltimore). 2016; 95 (6): e2838.

15. Long MJ, Papi E, Duffell LD, McGregor AH. Predicting knee osteoarthritis risk in injured populations.Clin Biomech (Bristol, Avon). 2017; 47: 87-95.

16. Veronese N, Stubbs B, Noale M, Solmi M, Luchini C, Maggi S. Adherence to the Mediterranean diet is associated with better quality of life: data from the Osteoarthritis Initiative. Am J Clin Nutr. 2016; 104(5): 1403-1409.

17. Lü J, Huang L, Wu X, Fu W, Liu Y. Effect of Tai Ji Quan training on self-reported sleep quality in elderly Chinese women with knee osteoarthritis: a randomized controlled trail. Sleep Med. 2017; 33: $70-75$.

18. Shmagel A, Onizuka N, Langsetmo L, Vo T, Foley R, Ensrud K, et al. Low magnesium intake is associated with increased knee pain in subjects with radiographic knee osteoarthritis: data from the Osteoarthritis Initiative. Osteoarthritis Cartilage. 2018; https://www.sciencedirect. com/science/article/pii/S106345841830102X?via\%3Dihub

19. Kwon SK, Sando R 3rd, Lewis TL, Hirabayashi Y, Maximov A, Polleux F. LKB1 Regulates Mitochondria-Dependent Presynaptic Calcium Clearance and Neurotransmitter Release Properties at Excitatory Synapses along Cortical Axons. PLoS Biol. 2016; 14(7): e1002516.

20. Morotti A, Charidimou A, Phuah CL, Jessel MJ, Schwab K, Ayres AM, et al. Association Between Serum Calcium Level and Extent of Bleeding in Patients With Intracerebral Hemorrhage. JAMA Neurol. 2016; 73(11): 1285-1290.

21. Louiset E, Duparc C, Lenglet S, Gomez-Sanchez CE, Lefebvre H. Role of cAMP/PKA pathway and T-type calcium channels in the mechanism of action of serotonin in human adrenocortical cells. Mol Cell Endocrinol. 2017; 441(5): 99-107.

22. Welch AA, Kelaiditi E, Jennings A, Steves CJ, Spector TD, MacGregor A. Dietary Magnesium Is Positively Associated with Skeletal Muscle Power and Indices of Muscle Mass and May Attenuate the Association Between Circulating C-Reactive Protein and Muscle Mass in Women. J Bone Miner Res. 2016; 31(2): 317-325.

23. Zeng C, Wei J, Terkeltaub R, Yang T, Choi HK, Wang YL, et al. Doseresponse relationship between lower serum magnesium level and higher prevalence of knee chondrocalcinosis. Arthritis Res Ther. 2017; 19(1): 236.

24. Veronese N, Stubbs B, Maggi S, Notarnicola M, Barbagallo M, Firth J, et al. Dietary Magnesium and Incident Frailty in Older People at Risk for Knee Osteoarthritis: An Eight-Year Longitudinal Study. Nutrients. 2017; 9(11): 1253.

25. Macdonald HM, Hardcastle AC, Jugdaohsingh R, Fraser WD, Reid DM, Powell JJ. Dietary silicon interacts with oestrogen to influence bone health: evidence from the Aberdeen Prospective Osteoporosis Screening Study. Bone. 2012; 50(3): 681-687.

26. Marcowycz A, Housez B, Maudet C, Cazaubiel M, Rinaldi G, Croizet K. Digestive absorption of silicon, supplemented as orthosilicic acidvanillin complex. Mol Nutr Food Res. 2015; 59(8): 1584-1589.

27. Jugdaohsingh R, Watson AIE, Pedro LD, Powell JJ. The decrease in silicon concentration of the connective tissues with age in rats is a marker of connective tissue turnover. Bone. 2015; 75:40-48.

28. Spector TD, Calomme MR, Anderson SH, Clement G, Bevan L, Demeester N, et al. Choline-stabilized orthosilicic acid supplementation as an adjunct to calcium/vitamin D3 stimulates markers of bone formation in osteopenic females: a randomized, placebo-controlled trial. BMC Musculoskelet Disord. 2008; 9: 85.

29. Choi MK, Kim MH. Dietary Silicon Intake of Korean Young Adult Males and Its Relation to their Bone Status. Biol Trace Elem Res. 2017; 176(1): 89-104. 
30. Jugdaohsingh R, Sripanyakorn S, Powell JJ. Silicon absorption and excretion is independent of age and sex in adults. Br J Nutr. 2013; 110(6): 1024-1030.

31. Geusens P, Pavelka K, Rovensky J, Vanhoof J, Demeester N, Calomme $\mathrm{M}$, et al. A 12-week randomized, double-blind, placebo-controlled multicenter study of choline-stabilized orthosilicic acid in patients with symptomatic knee osteoarthritis. BMC Musculoskelet Disord. 2017; 18(1): 2 .

32. Lewińska-Preis L, Jabłońska M, Fabiańska MJ, Kita A. Bioelements and mineral matter in human livers from the highly industrialized region of the Upper Silesia Coal Basin (Poland). Environ Geochem Health. 2011; 33(6): 595-611.

33. Ratcliffe S, Jugdaohsingh R, Vivancos J, Marron A, Deshmukh R, Ma JF, et al. Identification of a mammalian silicon transporter. Am J Physiol Cell Physiol. 2017; 312(5): C550-C561.
34. Wielkoszyński T. [Modified, spectrophotometric method of silicon determination in biological material]. Diagn Lab. 2000; 36(3): 377-385 (In Polish).

35. Rusak A, Karuga-Kuźniewska E, Wiatrak B, Szymonowicz M, Stolarski M, Radwan-Oczko M, et al. Venous insufficiency: Differences in the content of trace elements. A preliminary report. Adv Clin Exp Med. 2018; http://www.advances.umed.wroc.pl/ahead-of-print/68902.pdf

36. Bissé E, Epting T, Beil A, Lindinger G, Lang H, Wieland H. Reference values for serum silicon in adults. Anal Biochem. 2005; 337(1): 130-135.

37. Resmini G, Migliaccio S, Dalle Carbonare L, Sala U, Brama M, Fornari $\mathrm{R}$, et al. Differential characteristics of bone quality and bone turnover biochemical markers in patients with hip fragility fractures and hip osteoarthritis: results of a clinical pilot study. Aging Clin Exp Res. 2011; 23(2): 99-105.

38. Lee S. Endogenous parathyroid hormone and knee osteoarthritis: a cross-sectional study. Int J Rheum Dis. 2016; 19(3): 248-254. 12563. 